\title{
Morphological observations on the diapausing blastocyst of some macropodid marsupials
}

\author{
Meredith J. Smith \\ Department of Zoology, University of Adelaide, Adelaide, South Australia 5000
}

\begin{abstract}
Summary. Diapausing blastocysts from the uteri of females of 11 macropodid species were fixed, torn, flattened and stained for examination of the protoderm. The protoderm remained undifferentiated and unilaminar throughout diapause. The number of cells in the protoderm did not vary with age in Macropus rufus or $M$. eugenii. Protoderm cell number decreased slightly with age in $M$. rufogriseus banksianus and appeared to decrease in Potorous tridactylus. The diameter of the shell did not change appreciably with age, and the sizes of the blastocysts of different species were similar.
\end{abstract}

\section{Introduction}

Facultative embryonic diapause is a feature of reproduction in many macropodid marsupials. It is known to occur in at least 20 of the 50 or so extant species, and is absent in only one well-studied species, the western kangaroo, Macropus fuliginosus (Sharman, Calaby \& Poole, 1966; Calaby \& Poole, 1971; Maynes, 1973; Poole \& Catling, 1974). An obligate, seasonal embryonic diapause occurs in the tammar wallaby, $M$. eugenii, and Bennett's wallaby, $M$. rufogriseus fruticus (Berger, 1966; Catt, 1977).

Diapausing blastocysts of $M$. rufus were examined throughout lactation by light microscopy and found neither to increase in diameter nor undergo cell division (Clark, 1966). Those of $M$. giganteus were similar, even though formed late in lactation, not immediately post partum (Clark \& Poole, 1967). Whilst the size of diapausing blastocysts is available for some species (see Hughes, 1962; Tyndale-Biscoe, 1963; Berger, 1966; Renfree \& Tyndale-Biscoe, 1973), information on cell numbers is sparse and without indication of ranges. Studies of reactivated blastocysts of $M$. rufus show that the number of cells can increase to double that of diapausing blastocysts without increase in diameter (Clark, 1966, 1968). The morphological characteristics of diapausing blastocysts of several species are compared in the present paper.

\section{Materials and Methods}

Most of the blastocysts were obtained from females shot in the field in the course of other studies. Sometimes the reproductive system was removed and fixed in Bodian's fluid ( $80 \%$ alcohol, formalin, glacial acetic acid, 18:1:1 by vol.) and the blastocysts dissected out later. At other times the uterus was flushed with saline $(9 \mathrm{~g} \mathrm{NaCl} / \mathrm{l})$ and the blastocyst fixed separately in Bodian. The pouch young was weighed and measured and its age estimated from growth curves appropriate to the species.

Blastocysts were measured after fixation. They were then torn, flattened, stained with haematoxylin and mounted in neutral medium (Clark, 1966). The nuclei of the protoderm were counted from an accurate drawing of the protoderm made with the aid of a drawing tube. 
Blastocysts were obtained from the following females. Potorous tridactylus: 5 taken near Hobart, Tasmania, with pouch young aged between 48 and 98 days. Thylogale thetis: 1 taken near Armidale, New South Wales, with 82-day-old pouch young. Setonix brachyurus: 7, with pouch young from 15 to 65 days old were taken on Rottnest Island, Western Australia, in May, and 3 with larger pouch young were taken in August (2) or September. Macropus agilis: 1 from Cobourg Peninsula, Northern Territory, with a pouch young about 150 days old. $M$. dorsalis: 1 taken near Bonalbo, New South Wales, with 180-day-old pouch young. M. eugenii: 7 were taken on Kangaroo Island, South Australia, in June and July, and 12 between August and October. M. giganteus: 1 taken at Toganmain Station, New South Wales, with 229-day-old pouch young. $M$. rufogriseus banksianus: 3 taken near Goulbourn, New South Wales, 2 near Millicent, South Australia, and 18 near Bonalbo, New South Wales. Pouch young ranged in age from $<1$ week to about 270 days, and one young that had recently emerged permanently from the pouch was about 285 days old. $M$. rufogriseus fruticus: 6 were taken in the Florentine Valley, Tasmania, in July or September. Measurements of the pouch young were not available. $M$. robustus: 10 shot at Fowler's Gap, $110 \mathrm{~km}$ north of Broken Hill, New South Wales, with pouch young ranging in age from 15 to about 220 days. M. rufus: 16 shot at Mt Murchison, Tero Creek or Fowler's Gap, New South Wales, with pouch young ranging in age from 27 to 173 days. Wallabia bicolor: 3 taken near Bonalbo, New South Wales, and 1 with a newborn young at Port Welshpool, Victoria.

Table 1. Some characteristics of diapausing blastocysts of macropodid marsupials

\begin{tabular}{llll}
\hline \multicolumn{1}{c}{ Species } & $\begin{array}{c}\text { Time of blastocyst } \\
\text { formation }\end{array}$ & \multicolumn{1}{c}{ Shell diameter $(\mu \mathrm{m})$} & \multicolumn{1}{c}{$\begin{array}{c}\text { No. of protoderm } \\
\text { cells }\end{array}$} \\
\hline P. tridactylus & Post partum & $270 \pm 12 \cdot 3,250-280(5)$ & $107 \cdot 4 \pm 26 \cdot 8,83-143(5)$ \\
S. brachyurus & Post partum & $262 \pm 13 \cdot 7(21)^{*}$ & - \\
& & $276 \pm 27 \cdot 7,240-320(8)$ & $69 \cdot 4 \pm 2 \cdot 07,67-72(5)$ \\
M. agilis & Post partum & $250(1)$ & $77(1)$ \\
M. dorsalis & Pre or post partum & $250(1)$ & $52(1)$ \\
M. eugenii & Post partum & $264 \pm 22 \cdot 8(36) \dagger$ & - \\
& & $289 \pm 20 \cdot 3,240-320(18)$ & $86 \cdot 6 \pm 16 \cdot 7,61-118(10)$ \\
M. giganteus & Late lactation & $262 \pm 22 \cdot 8,226-308(16) \ddagger$ & $92 \pm 15 \cdot 1,68-113(9) \ddagger$ \\
M. robustus & Post partum & $317 \pm 37 \cdot 9,(10)^{*}$ & - \\
& & $305 \pm 19 \cdot 6,274-340(10)$ & $69 \pm 14 \cdot 0,58-88(4)$ \\
M. rufus & Post partum & $330 \pm 26 \cdot 0,260-380(32) \S$ & $85 \pm 9 \cdot 9,65-101(14) \S$ \\
& & $310 \pm 24 \cdot 7,280-360(13)$ & $91 \cdot 1 \pm 16 \cdot 1,62-129(13)$ \\
M. rufogriseus banksianus & Post partum & $301 \pm 45 \cdot 2,250-400(17)$ & $82 \cdot 1 \pm 21 \cdot 1,52-122(15)$ \\
M. rufogriseus fruticus & Post partum & $302 \pm 18 \cdot 3,280-320(6)$ & $58(1)$ \\
T. stigmatica & During lactation & $290(1)$ & $83(1)$ \\
W. bicolor & Pre partum & $300(1)$ & $75 \pm 19 \cdot 2,62-103(4)$ \\
\hline
\end{tabular}

Values are mean \pm s.d. and range for no. of specimens indicated in parentheses.

Data from * Tyndale-Biscoe (1963); † Renfree \& Tyndale-Biscoe (1973); † Clark \& Poole (1967); § Clark (1966).

PLATE 1

Fig. 1. Diapausing blastocyst of a sandy wallaby, Macropus agilis, carrying a 150-day-old pouch young. There are 77 cells, all with round nuclei. Scale line represents $100 \mu \mathrm{m}$.

Fig. 2. Diapausing blastocyst of a tammar wallaby, Macropus eugenii, during the non-breeding season. There are 61 cells, some with elongated nuclei. Scale as in Fig. 1. 


\section{PLATE 1}
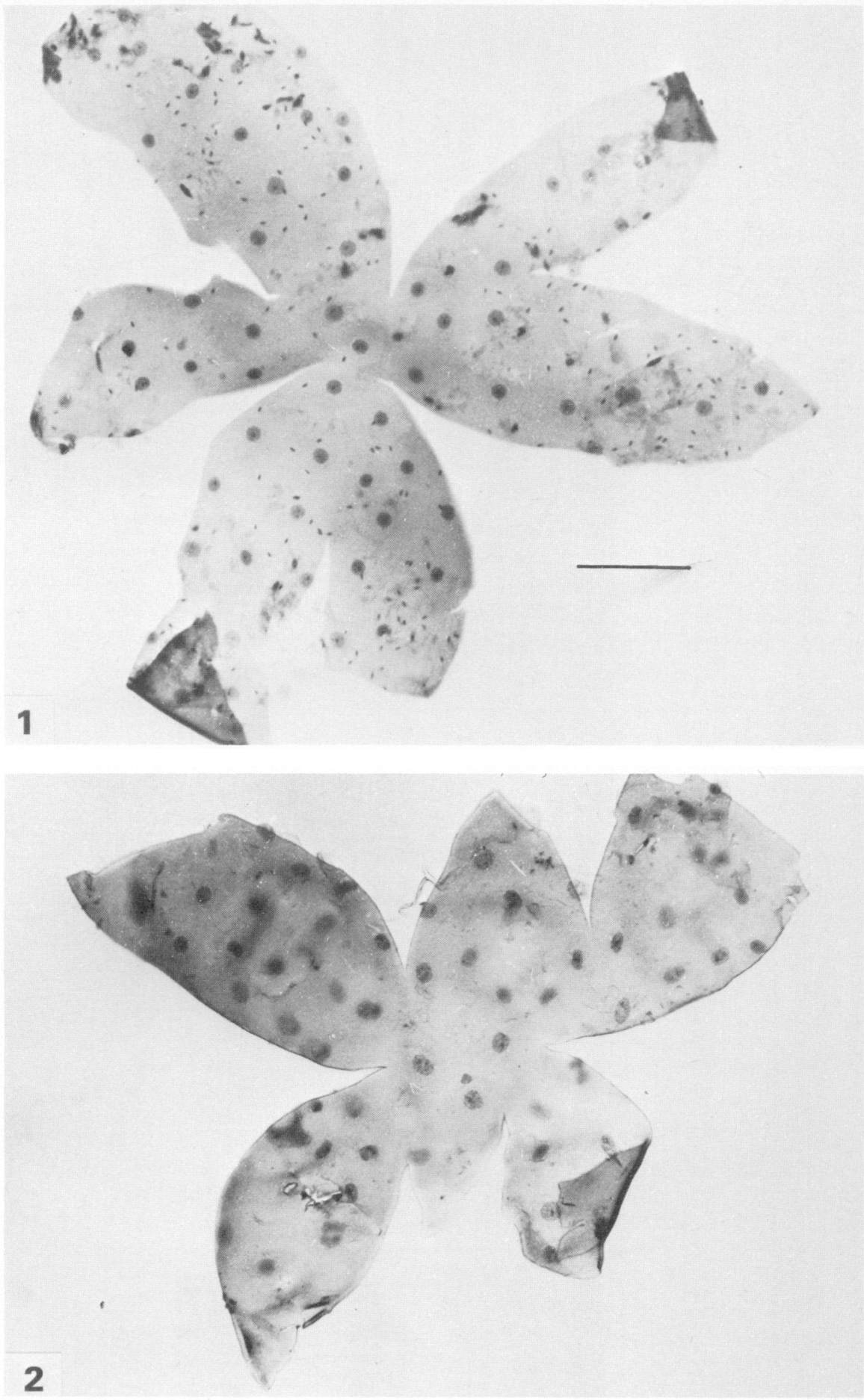

(Facing p. 484) 


\section{Results}

Outer shell diameters of diapausing blastocysts ranged from 226 to $400 \mu \mathrm{m}$ (Table 1) and in no species did diameter change significantly with age. The number of cells in the protoderm ranged from 52 to 143 (Table 1). Nuclei of the protoderm were all round in P. tridactylus, T. thetis, $S$. brachyurus, $M$. agilis (Pl. 1, Fig. 1), $M$. dorsalis, $M$. rufus and $W$. bicolor. Both round and elliptical nuclei occurred in the one blastocyst in M. eugenii (PI. 1, Fig. 2), M. rufogriseus and $M$. robustus, whilst $M$. giganteus blastocysts had both round and kidney-shaped nuclei. Dividing cells were not seen in any blastocyst from an animal with quiescent corpus luteum, and in all blastocysts the protoderm was unilaminar. In $M$. eugenii the nuclei in some blastocysts varied considerably in size, the largest nuclei having a diameter more than twice as great as the smallest. In the $13 \mathrm{M}$. rufus blastocysts for which cell numbers could be obtained, the number of cells did not vary significantly throughout the 200 days of diapause. Similarly in $M$. eugenii the number of cells did not vary significantly between early (range 72-96, mean $=83 \cdot 5, n=4$ ) and late $(61-118$, mean $=88 \cdot 6, n=6)$ stages of diapause. However, in M. rufogriseus banksianus the number of cells was less in older blastocysts (Text-fig. 1) and the slope of the regression line differed significantly from $0(P<0.01)$. A trend towards decrease in cell numbers was seen in $P$. tridactylus (Table 2) and in the specimen with a 72-day-old young a few cells of the blastocyst contained a small, pycnotic nucleus, apparently in a stage of degeneration. In $S$. brachyurus 2 blastocysts recovered during seasonal anoestrus in August showed no degenerative changes and did not have fewer cells than blastocysts recovered in the breeding season (May).

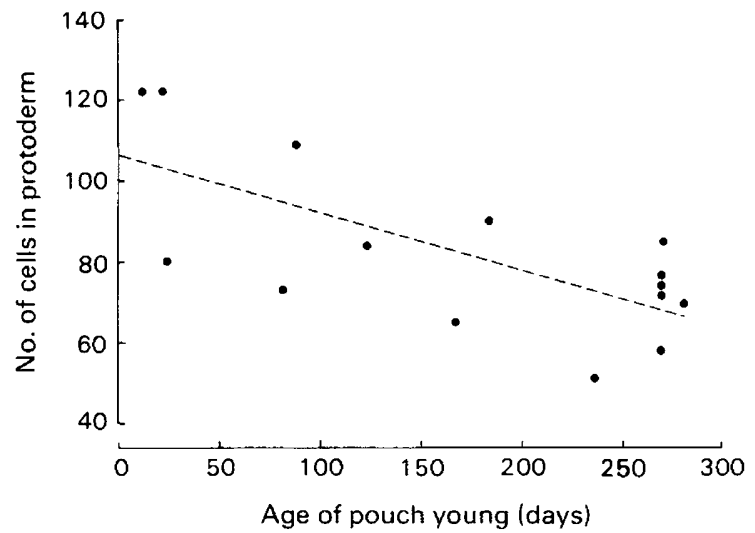

Text-fig. 1. Number of cells of protoderm of diapause blastocysts recovered during lactation from the red-necked wallaby, Macropus rufogriseus banksianus. The broken line is the mathematically fitted regression line.

Table 2. Size and cell numbers of blastocysts of 5 rat kangaroos (Potorous tridactylus) suckling pouch young

\begin{tabular}{ccc}
\hline $\begin{array}{c}\text { Age of pouch young } \\
\text { (days) }\end{array}$ & $\begin{array}{c}\text { Shell diameter } \\
(\mu \mathrm{m})\end{array}$ & No. of cells \\
\hline 48 & 280 & 143 \\
72 & 270 & 129 \\
86 & 270 & 83 \\
05 & 280 & 91 \\
98 & 250 & 91 \\
\hline
\end{tabular}

\section{Discussion}

The diapausing embryo shows a remarkable similarity between species of two macropodid subfamilies, irrespective of the stage of lactation when it is formed (Table 1). There is a complete 
arrest of cell division, and no increase in diameter during diapause. In M. rufogriseus banksianus and $P$. tridactylus there appears to be a slow loss of protoderm cells. In $M$. rufus, too, there is a trend towards lower cell numbers in older blastocysts, but this is not statistically significant, even when the results of the present study are combined with those of Clark (1966). However, in the species with the longest diapause, M. eugenii (Berger, 1966), no loss of cells was detected during diapause.

Blastocysts of $M$. eugenii in seasonal diapause were similar to those in lactational diapause, as would be expected from their continued viability during seasonal diapause. On the other hand, the normal, healthy appearance of $S$. brachyurus blastocysts in August was surprising in view of observations that blastocysts were not viable in August and later in the year (Shield \& Woolley, 1963).

The interval between removal of a pouch young and the birth of a young derived from a diapausing blastocyst is 31 days in $M$. rufus, only 2 days shorter than the gestation period (Sharman, 1963). Several other species, including Bettongia lesueur, Setonix brachyurus, $M$. eugenii, $M$. agilis and $M$. robustus, resemble $M$. rufus in having the delayed gestation period only 1 or 2 days shorter than the gestation period. On the other hand, the delayed gestation period in P. tridactylus is 29 days and the gestation period is 38 days, a difference of 9 days (Hughes, 1962; Shaw \& Rose, 1979). The difference is great in $W$. bicolor (7 days) and $M$. dorsalis (6 days) (Sharman et al., 1966; Smith, 1969). The suggestion by Rose (1978) that this large difference reflects a longer period of development before delay was not substantiated by the present observations of blastocysts of W. bicolor and M. dorsalis. P. tridactylus blastocysts may have entered diapause with a slightly greater number of cells but by the end of diapause the cell number was close to the mean value for other species.

I thank J. H. Calaby, W. E. Poole, J. C. Merchant and G. B. Sharman for providing me with blastocysts. I am grateful to $\mathrm{S}$. Barker for criticism of the manuscript.

\section{References}

Berger, P.J. (1966) Eleven-month "embryonic diapause" in a marsupial. Nature, Lond. 211, 435-436.

Calaby, J.H. \& Poole, W.E. (1971) Keeping kangaroos in captivity. Int. Zoo Yb. 11, 5-12.

Catt, D.C. (1977) The breeding biology of Bennett's wallaby (Macropus rufogriseus fruticus) in South Canterbury, New Zealand. N.Z. J. Zool. 4, 401-411.

Clark, M.J. (1966) The blastocyst of the red kangaroo, Megaleia rufa (Desm.), during diapause. Aust. J. Zool. 14, 19-25.

Clark, M.J. (1968) Termination of embryonic diapause in the red kangaroo, Megaleia rufa, by injection of progesterone or oestrogen. J. Reprod. Fert. 15, $347-355$.

Clark, M.J. \& Poole, W.E. (1967) The reproductive system and embryonic diapause in the female grey kangaroo, Macropus giganteus. Aust. J. Zool. 15, $441-459$.

Hughes, R.L. (1962) Reproduction in the macropod marsupial Potorous tridactylus (Kerr). Aust. J. Zool. 10, 193-244.

Maynes, G. (1973) Reproduction in the parma wallaby, Macropus parma Waterhouse. Aust. J. Zool. 21, 331-351.

Poole, W.E. \& Catling, P.C. (1974) Reproduction in the two species of grey kangaroos, Macropus giganteus
Shaw and $M$. fuliginosus (Desmarest). I. Sexual maturity and oestrus. Aust. J. Zool. 22, 277-302.

Renfree, M.B. \& Tyndale-Biscoe, C.H. (1973) Intrauterine development after diapause in the marsupial Macropus eugenii. Devl Biol. 32, 28-40.

Rose, R.W. (1978) Reproduction and evolution in female Macropodidae. Aust. Mammal. 2, 65-72.

Sharman, G.B. (1963) Delayed implantation in marsupials. In Delayed Implantation, pp. 3-14. Ed. A. C. Enders. University of Chicago Press.

Sharman, G.B., Calaby, J.H. \& Poole, W.E. (1966) Patterns of reproduction in female diprotodont marsupials. Symp, zool. Soc. Lond. 15, 205-232.

Shaw, G. \& Rose, R.W. (1979) Delayed gestation in the potoroo, Potorous tridactylus (Kerr). Aust J. Zool. 27, 901-912.

Shield, J. \& Woolley, P. (1963) Population aspects of delayed birth in the quokka (Setonix brachyurus). Proc. zool. Soc. Lond. 141, 783-790.

Smith, M.J. (1969) A study of embryonic quiescence in diprotodont marsupials. Ph.D. thesis, University of Adelaide.

Tyndale-Biscoe, C.H. (1963) The role of the corpus luteum in the delayed implantation of marsupials. In Delayed Implantation, pp. 15-28. Ed. A. C. Enders. University of Chicago Press. 